\title{
LEXICAL AND GRAMMATICAL FEATURES OF TEXTS ABOUT THE ARCHITECTURE OF ANCIENT EGYPT
}

\author{
Olena Mospan \\ PhD in Philology, Associate Professor \\ Kharkiv National University of Civil Engineering \\ and Architecture (KNUCEA) \\ (Kharkiv, Ukraine) \\ e-mail: elena.mospan@gmail.com
}

\begin{abstract}
Annotation. The article deals with the analysis of lexical and grammatical features of texts on the history of architecture - one of the basic academic disciplines that future architects are taught. The aim of the research is to increase the level of readiness of foreign students to perceive professional information. The subject of research is typical for the scientific and technical style of speech and linguistic features specific to the historical and architectural discourse. The typical structures of texts on the architecture of Ancient Egypt are described. The most frequent lexical thematic groups of nominal and verbal vocabulary are highlighted in this discourse; the compatibility of frequency substantive units is analyzed. The main syntactic features of the historical and architectural discourse describing the ancient Egyptian era are listed. Recommendations on the selection of educational texts for foreign students of basic faculties and the system of pre- and post-text assignments for them are given.
\end{abstract}

Key words: architectural discourse, linguistic features of discourse, lexical-grammatical group, subjectpredicate relations, determinative relations.

\section{ЛЕКСИКО-ГРАММАТИЧЕСКИЕ ОСОБЕННОСТИ ТЕКСТОВ ОБ АРХИТЕКТУРЕ ДРЕВНЕГО ЕГИПТА}

\author{
Е.П. Мосьпан \\ кандидат филологических наук, доцент \\ Харьковский национальный университет \\ строительства и архитектуры (ХНУСА) \\ (Харьков, Украина) \\ e-mail: elena.mospan@gmail.com
}

\begin{abstract}
Аннотация. Статья посвящена анализу лексических и грамматических особенностей текстов по истории архитектуры - одной из базовых учебных дисциплин, которую преподают будущим архитекторам. Целью исследования является повышение уровня готовности иностранных учащихся к восприятию профессиональной информации. Предмет изучения общие для научно-технического стиля речи и специфические для историко-архитектурного дискурса языковые особенности. Описана типичная структура текстов по архитектуре Древнего Египта. Выделены наиболее частотные в данном дискурсе лексико-тематические группы именной и глагольной лексики; проанализирована сочетаемость частотных субстантивных единиц. Отмечены основные синтаксические особенности историко-архитектурного дискурса, описывающего древнеегипетскую эпохе. Даны рекомендации по
\end{abstract}


отбору учебных текстов для иностранных студентов базовых факультетов и системе до- и послетекстовых заданий к ним.

Ключевые слова: архитектурный дискурс, языковые особенности дискурса, лексико-грамматическая группа, субъектно-предикатные отношения, определительные отношения.

ВВЕДЕНИЕ. Одной из основных задач преподавателей языковой подготовки, работающих на базовых факультетах, является облегчение процесса восприятия иностранными студентами специальной информации с выведением их в профессионально ориентированную подготовленную и неподготовленную научную речь. С целью ее выполнения для иностранных студентов разрабатываются разнообразные учебные материалы по обучению языку специальности.

ОБЗОР ЛИТЕРАТУРЫ. Традиции создания пособий по научному стилю речи были заложены в 70-80-ых годах прошлого века. Данное направление активно разрабатывается и сейчас. Время показало, что одним из путей совершенствования учебных материалов по научному стилю речи является их максимальное приближение к учебно-профессиональным потребностям студента. Так, сначала создавались пособия общеинженерного профиля, а позднее появились отдельные учебники для инженеров-техников, инженеров-экономистов и т.п., затем и более специализированные издания - для будущих строителей, архитекторов, программистов и т.п. При том, что уже накоплен большой опыт создания такого рода пособий, существуют резервы их улучшения. Один из них - применение в процессе их создания результатов лингвистического анализа текстов учебников по базовым дисциплинам. Так, харьковский русист В.В. Левитский еще в 1966 году первым в отечественной методике РКИ составил частотный словарь лексики учебников для первокурсников медицинских вузов (Levitskiy 1966, 184) и изложил в диссертации принципы ее лингвостатистического описания (Levitskiy 1971, 267). Его идеи были развиты в работах Э.В. Левитской (Витковской), чья диссертация была посвящена функциональной значимости и сочетаемостной активности именной лексики в газетном дискурсе (Levitskaya 1985, 237). Научные выводы этих специалистов составляют теоретическую базу данной работы. Она выполнена в лингвометодическом ключе, при том, что архитектурный дискурс в большинстве становится объектом лингвистического или текстологического описания (Van Li 2011, 107 - 116; Kositskaya, Zaytseva 2015, 142 -146; Loginova 2013; Petrova 2015).

ЦЕЛЬ. Целью исследования является приближение занятий по языковой подготовке к реальным ситуациям учебного общения студентов и преподавателей профильных дисциплин, повышение уровня готовности иностранных учащихся к восприятию профессиональной информации. Для этого была поставлена задача проанализировать тексты - описания архитектурных памятников Древнего Египта в рамках курса истории архитектуры (Biryukova 2005, 366; Vseobschay 1970, 512; Loginova 2013) на предмет выявления общих для научно-технического стиля речи и специфических для историкоархитектурного дискурса содержательных и лексико-грамматических особенностей. Данная работа является частью комплексного изучения языковых особенностей базовых для будущих архитекторов специальных дисциплин. 
МЕТОДЫ. В процессе исследования применялись метод сплошной частотной выборки, аналитический метод изучения семантики отобранных единиц, а также описательноинтерпретационный метод.

ОБЪЕКТ. Тексты по истории архитектуры были выбраны в качестве объекта изучения в связи с тем, что этот предмет является одним из важнейших в процессе подготовки будущих архитекторов. Как правило, именно из учебных пособий по этой дисциплине преподаватели языковой подготовки отбирают на начальном этапе работы тексты для обучения будущих архитекторов научному стилю речи, дорабатывая их с учетом уровня речевой компетенции иностранных студентов. Учебный материал этого курса традиционно подается в соответствии с историко-географическим принципом: архитектура Древнего мира, Средних веков, европейская архитектура эпох барокко, классицизма, модерна и т.д. Первым подробно рассматривается Древний Египет, что и обусловило выбор объекта данного исследования.

РЕЗУЛЬТАТЫ. Анализ учебных материалов показал, что тексты о Древнем Египте состоят из двух содержательных частей: 1) вводной, которая включает указание места и времени возникновения и развития данной культуры, ее периодизацию, краткую социальнополитическую и экономическую характеристики эпохи и 2) собственно историкоархитектурной, содержащей детальное описание отдельных архитектурных памятников. Подобным образом представлены почти все периоды, т.е. такая структура является характерной чертой текстов данной тематики. Именно семантическая структура текста объясняет активное использование географических и исторических номинаций, таких, как Средний, Поздний Египет, Верхний и Нижний Египет, Нил, Суэикий канал, Ассуанское море (водохранилище), Нубийские скаль, Мемфис, Фивы, Луксор, Гиза, Абу-Симбел, Саккара, Дашур, Дейр-эль-Бахри, включая имена правителей, богов и т.п.: Дюжоссер, Снофру, Хеопс, Хефрен, Рамзес, Тутанхомон, Амон, Озирис, Ра, Исида, преимущественно в сочетании с названиями строений: пирамида Джоссера, храм Амона, усыпальница Рамзеса II, гробница Тутанхамона. Подобная лексика, которая усваивается еще на школьных уроках истории, в иностранной аудитории требует отдельной отработки, во-первых, ввиду того, что подобные номинации, как правило, отличаются по звуковой форме в разных языках, а во-вторых, в связи с тем, что необходимым минимумом исторических знаний по разным причинам обладают далеко не все иностранные учащиеся. Следует также вводить и русскоязычные наименования представителей разных классов, государственных должностей, постов и т.П., такие, как фараон, царь, царица, жрец, аристократия, придворные, приближенные и др.

Специфические для данного дискурса лексические группы составляют: 1) названия животных и птиц, включая мифических: сфинкс; бык, овца, ибис, скарабей и др., считавшихся священными, что объясняет создание их скульптурных и живописных изображений в древние времена, а также 2) наименования растений и их частей, которые в Древнем Египте использовались в качестве стройматериалов или служили образцами при создании отдельных архитектурных объектов: камым, лотос, тростник, пальма, ствол, стебель, иветок, бутон. Некоторые из этих ботанических терминов стали структурными элементами названий типов колонн египетского ордера: пальмовидная, папирусовидная $u$ лотосовидная. (Названия еще двух типов колонн образованы имен богов: гиторическая - от богини красоты Гатор (или Затор) и осирическая - от бога Осириса.)

Основной же массив специальной лексики в анализируемом дискурсе предсказуемо составляют строительные и архитектурные термины. В анализируемых текстах широко используются названия строений, строительных объектов и изделий: дворец, усадьба, хижина, квартал, лабиринт, храм, молельня, сокровищница, обелиск и т.п. и их конструктивных частей: колонна, полуколонна, колоннада, галерея и др. В этой 
тематической группе выделяются номинации специфических религиозных и погребальных сооружений и помещений: некрополь, пирамида, гробнища, саркофаг и под. Студенту с начальной языковой подготовкой, скорее всего, знакомы слова окно, пол, потолок, стена, комната, коридор, лестнииа, этаж, двор, бассейн, дорога, как, возможно, и номинации крыша, ступеньки, площадка, квартал и т.п., но лексемы столб, балка, плита перекрытия, терраса, цоколь, вестибюль, ярус, насыпь, вал, пандус, портик, пилон, башня, цјоколь, представляющие частотную профессиональную лексику, необходимо будет постепенно, с учетом их частотности, особенностей синтагматики и др., вводить в активный профессиональный лексикон иностранного учащегося.

Bсе тексты, описывающие какой-либо архитектурный памятник, содержат названия стройматериалов и строительных изделий из них, которые использовались на описываемом этапе развития строительства и архитектуры. В данном случае это номинации песок, глина, раствор, кирпич, кирпич-сыреч, фаянс и фаянсовая плитка, известь, дерево, бревно, известняк и блоки известняка, алебастр и алебастровые плиты, гранит, диорит и т.п. Они функционируют, как правило, в конструкциях с родительным падежом и в сочетании со специальной глагольной лексикой. Такие глаголы, как правило, называют способы создания и отделки архитектурных объектов или их отдельных конструктивных элементов: использовать / применять песок, тростник, возводить из камня, класть кирпич, делать из известняка, обмазывать глиной, облицовывать / отдельвать плитами, камнем, выкладывать плиткой, вытесать из камня, подогнать каменные блоки и пр. Сюда же следует отнести и такие предикаты, как сформировать (комплекс), украсить (полуколоннами), возвести (обелиск), ориентировать (пирамиду) и т.п. Эта глагольноименная лексика, имеющая высокую частотность, является базовой для будущих архитекторов и используется при описании следующих периодов в истории архитектуры. Поэтому работу над перечисленными тематическим группами следует сделать регулярной, постепенно подключая названия строений, материалов и технологий, характерных для последующих эпох, и уделяя особое внимание их парадигматике и синтагматике.

Особенностью архитектурного дискурса, как научного изложения, посвященного творческой деятельности, является функционирование эмоциональных и экспрессивных элементов, что отличает этот тип дискурса от естественнонаучного и сближает его с искусствоведческим. Эта характерная черта объясняется тем, что воздействие архитектурного объекта на человека является одной из основных целей его создателей. Способы выражения эмоциональной и экспрессивной оценки требуют отдельного описания, а системно обучать им следует, вероятно, не ранее второго курса, так как необходимо сначала изучить то, что оценивается. К оценочным средствам следует отнести такие номинации и выражения, как возвышиатся, доминирует, подавляет, шедевр строительного искусства, грандиозный проект, роскошный двореи, «мать всех пирамид», «отеи трепета» и многие другие.

Как известно, дошедшие до нашего времени архитектурные памятники данной эпохи включают пирамиды, скальные храмы, подземные гробницы и развалины жилых построек храмов, дворцов, усадеб аристократов. Пирамиды на разных исторических этапах отличались ориентацией в пространстве, использованным для их строительства материалом, конструкцией надземной части, в частности, формой крыши и стен, количеством ярусов, облицовкой, а также организацией внутреннего пространства и его отделкой, несущими конструктивными и декоративными элементами, наличием сопутствующих построек храмов, молелен и т.п. Как правило, в учебных текстах, посвященных этому периоду, описывается одна из пирамид - чаще всего пирамида Хеопса - самая известная в наше время. Если дополнить учебный материал заданиями на описание других пирамид с акцентом на их сходство и отличия, то можно существенно расширить словарный запас учащихся и повысить их речевую активность, так как при этом будет происходить перенос сформированных речевых навыков. Например, можно предложить студентам в устной или 
письменной форме рассказать (с опорой на справочную информацию и базовые лексикограмматические конструкции) о времени их создания, размерах, материале, из которого они сложены, о том, как соединяются между собой консруктивные элементы, чем пирамиды отделаны снаружи, какие подземные помещения и системы они имеют, где в них расположен саркофаг, есть ли внутри и вблизи скульптурные изображения и т.п. Для развития устной и письменной речи также целесообразно включать в учебные пособия дополнительные учебные тексты более высокого уровня сложности. Их можно будет использовать как в аудитории, так и для самостоятельной работы в сильных группах. Именно лингвистический анализ учебных пособий по соответствующей дисциплине предмету позволяет установить тематику и лексико-грамматическое наполнение подобных текстов.

Освоение лексики подразумевает работу со словообразовательными рядами. С этой точки зрения, методический интерес в текстах по архитектуре Древнего Египта представляют следующие ряды производных простых и сложных прилагательных: додинастический (период), подопорная (стена), подземная / наземная (часть); гипостильный / перистильный (зал), протодорические (колонны); пилонообразный (откос), тоннелеобразная (камера); папирусовидная, лотосовидная, пальмовидная (колонна); прямоугольный (столб), полускальная (усыпальница), овцеголовый (сфинкс), многоколонный (зал), трехступенчатая, семиступенчатая (пирамида), четьрехгранный (столб), двадиатиметровая (скульптура) и др. В текстах также встречается ряд сложных существительных, образованных словосложением: кирпич-сырец, женщина-фараон, город-крепость, город-некрополь, лучируки, рисунок-текст, структурные элементы которых, за исключением последней номинации, склоняются по разным морфологическим моделям, на что необходимо обратить внимание иностранных учащихся.

C точки зрения синтаксиса, специфика анализируемого дискурса заключается, в первую очередь, в особенностях выражения субъектно-предикатных отношений. В исследуемых текстах широко представлены характерные для научного дискурса неопределенно-личные активные конструкции, такие, как: При входе размещали статуи быков; Во внутренней отделке использовали камень; В наземной части размещуют заупокойные храмы; Через Нил камень переправляли на плотах, и пассивные конструкции несовершенного и совершенного вида: Храм строился на протяжении почти тысячи лет; Камень доставлялся из каменоломен; Дороги обсаживаются пальмами; Пирамида Джоссера построена на месте другой пирамиды; Впервые в архитектуре был сформирован архитектурный комплекс; Пирамиды правильно ориентированы, Вход был оформлен бамнями и т.п.

При этом было отмечено наличие значительного количества двусоставных активных конструкций, используемых в основном в следующих ситуациях: 1) в вводной части текста, где дается характеристика эпохи: Египетская культура возникла на узкой полосе плодородной земли долинь Нила; Народные восстания и борьба за власть отделяют Древнее и Среднее царства; Формирование египетского государства значительно отличалось от Междуречья; 2) в конструкциях, характеризующих отдельные строения и их элементы: колонны имели высоту ..., зал имел ширину ... и высоту ...; Наиболее роскошным был двореи Аменхотепа III; 3) в предложениях, где указывается автор проектов или инициатор строительства описываемых объектов: Каждый фараон строил новую резиденцию; Вокруг главной постройки Имхотеп разместил дворы; В храме женщиныфараона архитектор Сененмут применил гаторические колонны с головками богини Хатор и т.п. Распространенность таких структур специфична для исследуемого типа дискурса и сближает его с историческими и искусствоведческими текстами, в которых важен автор анализируемого произведения, чья личность оказывает определяющие влияние на результат деятельности.

Определительные отношения в текстах по архитектуре Древнего Египта представлены на уровне субстантивных словосочетаний типа шалаш из прутьев, здания из кирпича-сыриа, 
раствор из глины, извести и песка, облицовка из известняка, статуя фараона, молельня со cтатуей, адъективно-субстантивными конструкциями, в том числе и с оценочным значением: династический период, пирамидальная форма, ступенчатая пирамида, египетский ордер, папирусообразные колонны, погребальный комплекс, а также причастными конструкциями, в которых преобладают пассивные формы: некрополи, облицованные каменными плитами; гробницы, называемые «мастаба»; блоки, держащиеся за счет силь тяжести; глиняные модели, сохранившиеся в захоронениях; фараон, оставивший описание своего двориа и т.п.

Определительные причастные конструкции - одна из особенностей научно-технического текста; в нашем случае в процессе их активизации необходимо обратить внимание на наполнение их частотной профессиональной лексикой. Обилие причастных оборотов и предикатов, выраженных краткой формой пассивного причастия, делают актуальной повторительную работу по их дифференциации. Этот материал, который обычно осваивается в рамках подготовительного языкового курса, на базовых факультетах следует регулярно активизировать с привлечением специальных лексических единиц. В процессе этой работы следует проанализировать, например, такие парные конструкции: $B$ доисторический период строились хижины, обмазанные глиной. - Стены хижин были обмазаны глиной; Позже появились здания, сложенные из кирпича. - Этот дом был сложен из кирпича; Статуи фараона были выполнень из черно-зеленого диорита. - Вдоль стен пирамиды стояли выполненные из черно-зеленого диорита статуи фараона; Храмовая дорогая обсажена пальмами. - К храму вела дорога, обсаженная пальмами и т.п.

ЗАКЛЮЧЕНИЕ. Работу с выделенными группами номинаций и специфическими типами синтаксических конструкций следует проводить на этапах пред- и послетекстовых заданий, делая ее системной. Исследование предполагается продолжить, и по его результатам составить учебный словарь лексики, обслуживающей разделы пособий, посвященные архитектуре Древнего мира.

\section{LIST OF REFERENCES}

Biryukova, N.V. (2005). Istoriya arhitekturyi : uchebnoe posobie [dlya srednih spetsialnyih uchebnyih zavedeniy po spetsialnosti 2901 "Arhitektura"] / Biryukova N.V. - Moskva : INFRA-M, $366 \mathrm{~s}$.

Chepelik V.V.Zodchie Srednevekovya i novogo vremeni (UI-HIHvv.): Uchebnoe posobie. - K.: UMK VO, 1991. - 124 s. - Na ukr. yazike.

Van Li. (2011). Grammaticheskaya spetsifika nauchnyih tekstov russkogo / Van Li. - Vestnik Kemerovskogo gosudarstvennogo universiteta. - 2011. - \#. 17. - Ch. I. - S. 107 - 116.

Vseobschaya istoriya arhitekturyi v 12 tomah. Tom 1 : Arhitektura drevnego mira / Pod redaktsiey O. H. Halpahchyana (otvetstvennyiy redaktor), E. D. Kvitnitskoy, V. V. Pavlova, A. M. Pribyitkovoy. - Vtoroe izdanie, ispravlennoe i dopolnennoe. - (1970), 512 s., il.

Kositskaya, F.L., Zaytseva, I.E. (2015). Arhitekturnyiy diskurs i ego zhanryi v sfere professionalnoy kommunikatsii (na materiale frantsuzskogo yazyika) / F.L. Kositskaya F.L., I.E. Zaytseva I.E. - Vestnik TGPU 2015 \#4 (157).- S. 142 -146.

Levitskaya, E. V. (1985). Funktsionalnaya znachimost i sochetaemostnaya aktivnost imennoy leksiki v russkom yazyike : dis. ... kand. filol. nauk : 10.02.01 / E. V. Levitskaya. - H., 237 s. 
Levitskiy, V. V. (1966). Chastotnyiy slovar yazyika uchebnyih posobiy meditsinskogo instituta : (Pervyiy semestr) / [sost. V. V. Levitskiy]. - Moskva : Izd. Mosk. un-ta, 184 s.

Levitskiy, V. V. (1971). Lingvostatisticheskoe opisanie leksiki nauchnoy rechi (na materiale uchebnikov medinstituta) : dis. ... kand. filol. nauk / nauch. ruk. G. I. Makarova ; HGU / V. V. Levitskiy. - Harkov, 267 s.

Loginova, D. V. (2013). Istoriya arhitekturyi [Elektronnyiy resurs] : uchebnoe posobie : samost. ucheb. elektron. izd. / D. V. Loginova ; Syikt. lesn. in-t. - Elektron. dan. - Syiktyivkar : SLI, Rezhim dostupa: http://lib.sfi.komi.com. - Zagl. s ekrana. [posl. obraschenie 14.03.2021].

Mospan, E., Bessonova, N. \& Greul, O (2020). Teaching the scientific style of the rivers of the future architects and builders in KNUCA: achievements, problems, perspectives // International Scientific-Pedagogical Organization of Philologists “ WEST-EAST ” (ISPOP). Scientific Journal "WESTEAST". Vol. 4, N1 (October, 2020). pp. 70-77. https://doi.org/10.33739/2587-5434-2020-3-70-77

Petrova, L.A. (2015). Arhitekturno-stroitelnyiy diskurs kak samostoyatelnyiy ob'ekt lingvisticheskogo rassmotreniya [Elektronnyiy resurs] / L.A. Petrova . - Evraziyskiy soyuz uchenyih. - Filologicheskie nauki. Rezhim dostupa: https://euroasia-science.ru/filologicheskienauki/\%D0\%B0\%D1\%80\%D1\%85\%D0\%B8\%D1\%82\%D0\%B5\%D0\%BA\%D1\%82\%D1\%8 $3 \% \mathrm{D} 1 \% 80 \% \mathrm{D} 0 \% \mathrm{BD} \% \mathrm{D} 0 \% \mathrm{BE}-$

$\% \mathrm{D} 1 \% 81 \% \mathrm{D} 1 \% 82 \% \mathrm{D} 1 \% 80 \% \mathrm{D} 0 \% \mathrm{BE} \% \mathrm{D} 0 \% \mathrm{~B} 8 \% \mathrm{D} 1 \% 82 \% \mathrm{D} 0 \% \mathrm{~B} 5 \% \mathrm{D} 0 \% \mathrm{BB} \% \mathrm{D} 1 \% 8 \mathrm{C} \% \mathrm{D} 0$ $\% \mathrm{BD} \% \mathrm{D} 1 \% 8 \mathrm{~B} \% \mathrm{D} 0 \% \mathrm{~B} 9-$

\%D0\%B4\%D0\%B8\%D1\%81\%D0\%BA\%D1\%83\%D1\%80\%D1\%81-\%D0\%BA/

Onkovich, G. V., Chepelik, V. V. (2011). Ukrayinska mova dlya arhitektoriv. I ne tilki : navch. posib. /; NAPN Ukrayini, In-t vish'. osviti. - Kiyiv : Logos, $220 \mathrm{s.}$

Onkovich, A.V. (1980). Metodicheskie ukazaniya po razvitiyu rechi dlya studentov-inostrancev stroitelnih i arhitekturnih specialnostei. Professiya? - Stroitel! / Kiev. inzh.-stroit. in-t ; sost. A. V. Onkovich. - Kiev : KISI, $52 \mathrm{~s}$.

Onkovich, A. V.Starinskaya, N. N. (1985). Metodicheskie rekomendacii k zanyatiyam po specleksike dlya studentov-inostrancev podgotovitelnogo fakulteta arhitekturnoi specialnosti /; Kiev. inzh.-stroit. in-t. - Kiev : KISI, $36 \mathrm{~s}$.

Simonenko, M.A. (2008). Arhitekturnyiy diskurs vs diskurs arhitekturyi / E.M. Simonenko Obschestvennyie i gumanitarnyie nauki. T. 1. - \# 38 (82) , $315-319$ s.

\section{For citation:}

Mospan, E. (2021) lexical and grammatical features of texts about the architecture of ancient Egypt // International Scientific-Pedagogical Organization of Philologists "WEST-EAST " (ISPOP). Scientific Journal "WEST-EAST". Vol. 5, N1 (March, 2021). pp. 113-119. https://doi.org/10.33739/2587-5434-2021$\underline{3-1-113-119}$

\section{Для цитирования:}

Мосьпан, Е.П. (2021) Лексико-грамматические особенности текстов об архитектуре Древнего Египта // International Scientific-Pedagogical Organization of Philologists "WEST-EAST" (ISPOP). Scientific Journal "WEST-EAST". Vol. 5, N1 (March, 20201). C. 113-119. https://doi.org/10.33739/25875434-2021-3-1-113-119 
Information about the author:

Elena Mospan - PhD, Associate Professor of the Department of Ukrainian Language and Language Training of Foreign Citizens, Kharkiv National University of Construction and Architecture (KNUCEA), Kharkiv, Ukraine.

e-mail: elena.mospan@gmail.com

\title{
Сведения об авторе:
}

Елена Павловна Мосьпан - кандидат филологических наук, доцент кафедры украинского языка и языковой подготовки иностранных граждан, Харьковский национальный университет строительства и архитектуры (ХНУБА), Харьков, Украина.

электронная почта: elena.mospan@gmail.com

Manuscript received: $12 / 01 / 2021$

Accepted for publication: 15/02/2021

Рукопись получена: 12/01/2021

Принята к печати: 15/02/2021

\author{
International Scientific-Pedagogical Organization of Philologists "West-East" - ISPOP \\ SCIENTIFIC JOURNAL "WEST-EAST" \\ ISSN (print) - 2587-5434 ISSN (online) - 2587-5523
}

